\title{
Neuroepithelial Cell
}

National Cancer Institute

\section{Source}

National Cancer Institute. Neuroepithelial Cell. NCI Thesaurus. Code C41410.

A cell found in the nervous system. It includes glial cells, neuroblasts, and olfactory cells. 